\title{
AUAG Machining Mechanism and Experimental Study of SiN Brittle Materials
}

\author{
Chunfang Xiao \\ Changsha Aeronautical Vocational and Technical College, Changsha, China \\ Email:xcf553017423@qq.com
}

How to cite this paper: Xiao, C.F. (2021) AUAG Machining Mechanism and Experimental Study of SiN Brittle Materials. Open Access Library Journal, 8: e8143.

https://doi.org/10.4236/oalib.1108143

Received: November 1, 2021

Accepted: November 23, 2021

Published: November 26, 2021

Copyright $\odot 2021$ by author(s) and Open Access Library Inc.

This work is licensed under the Creative Commons Attribution International License (CC BY 4.0).

http://creativecommons.org/licenses/by/4.0/

\section{(c) (i) Open Access}

\begin{abstract}
In this paper, it is studied that the processing mechanism of SiN brittle material in Axial Ultrasound Vibration Assisted Grinding. Search for the relationship between machine tool system and ultrasonic system in AUAG machining, and establish the mathematical model of system matching. The importance of system matching for AUAG machining is verified by the influence of ultrasonic parameters on grinding force and workpiece surface quality. I verify the correctness of the theory. The matching model of ultrasonic system can be used to optimize the ultrasonic processing parameters of hard and brittle materials, predict the grinding surface morphology, grinding force and surface roughness.
\end{abstract}

\section{Subject Areas}

Applied Physics

\section{Keywords}

SiN, Brittle Material, Machining, Mechanism of AUAG System Matching Model, Experiment, Results and Discussions

\section{Introduction}

$\mathrm{SiN}$ is a typical brittle material. It is an important structural ceramic material and superhard material. It has lubricity, wear resistance and oxidation resistance at high temperature. SiN ceramics are often used to manufacture mechanical components such as bearings, turbine blades, mechanical seal rings, permanent dies and so on because of their excellent properties. Taking the processing of silicon nitride as an example, this paper studies the AUAG processing of brittle materials and verifies the correctness of the theory [1]-[6]. 


\section{Matching Model of Ultrasound Machining System for Brittle Materials}

\subsection{Modeling of Critical Ultrasound Vibration Frequency}

The mathematical model of ultrasonic vibration frequency can provide powerful guidance for the establishment and design of special ultrasonic processing system, reveal the range of resonant frequency used in ultrasonic processing, and provide effective theoretical basis for how to select the optimal processing parameters in actual processing. $R$ represents the radius and $a_{p}$ represents the cutting depth.

As shown in Figure 1, the contact time t1 between Contact time between abrasive particles and workpiece in a single grinding wheel rotation cycle can be calculated according to the speed, diameter and cutting depth of the grinding wheel:

$$
t_{1}=\frac{\arccos \frac{R-a_{p}}{R}}{\omega}
$$

As shown in Figure 2 and Figure 3, when the arc surface of the grinding wheel contacting the workpiece in a single cycle is covered by the vibration trajectory of the abrasive in ultrasonic machining, the arc length L1 equals the sum of the transverse crack width of the abrasive in all ultrasonic vibration periods.

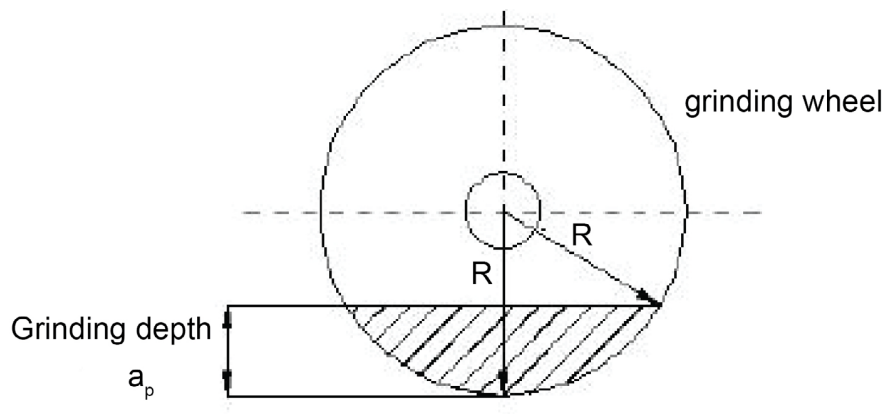

Figure 1. Wheel grinding depth sketch map.

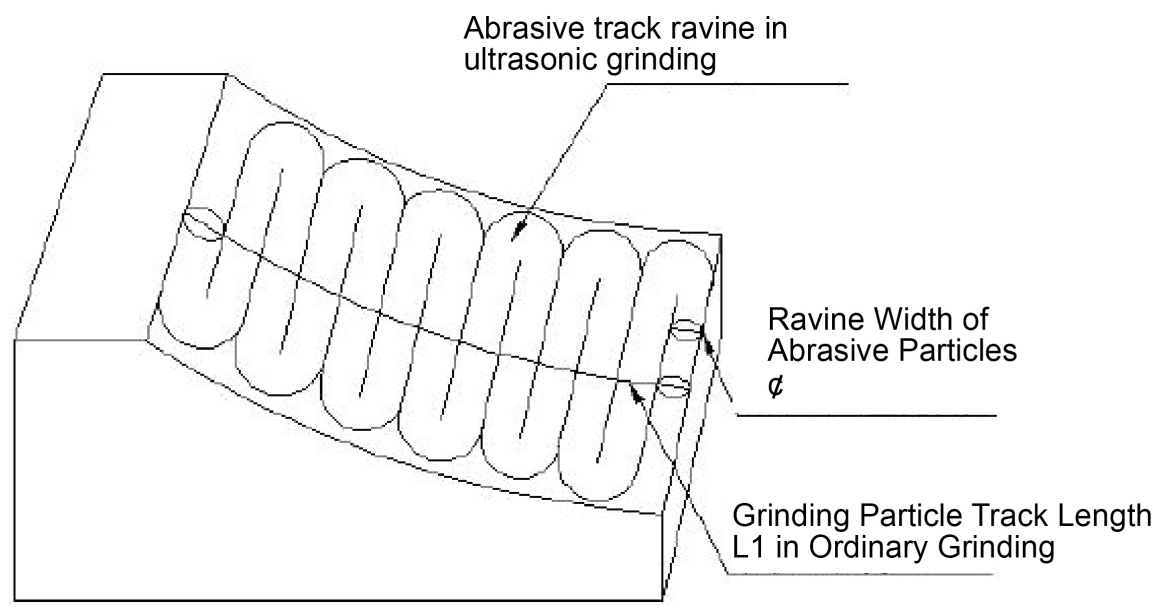

Figure 2. Grain track under ultrasonic vibration on the grinding curved surface. 


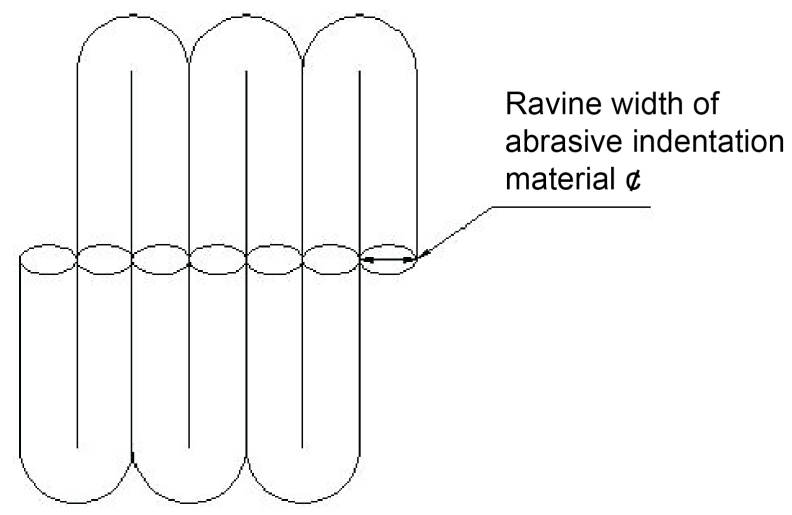

Figure 3. The critical path of single grain in UAG.

The length of transverse crack $\mathrm{C}_{1}$, vibration frequency $\mathrm{f}$, number of transverse cracks $\mathrm{n}$, number of ultrasonic vibration times $\mathrm{m}$ experienced on the arc, and time $t_{1}$ of grinding wheel contact with workpiece in a single cycle can be obtained as follows:

$$
\begin{gathered}
L_{1}=n C_{1} \\
n=2(2 m+1) \\
L_{1}=t_{1}\left(v_{s}+v_{m}\right) \\
m=t_{1} f \\
n=2\left(2 t_{1} f+1\right) \\
t_{1}\left(v_{s}+v_{w}\right)=2 C_{1}\left(2 t_{1} f+1\right)
\end{gathered}
$$

The critical ultrasonic vibration frequencies obtained by the simultaneous formulas (9), (14), (15)-(20) are as follows:

$$
f=\frac{t_{1}\left(v_{s}+v_{w}\right)-2 C_{1}}{4 C_{1} t_{1}}=\frac{\arccos \frac{R-a_{p}}{R}\left(v_{s}+v_{w}\right)-2 w \xi_{1}\left(\frac{P_{m}}{K_{c}}\right)}{4 \arccos \frac{R-a_{p}}{R} \xi_{1}\left(\frac{P_{m}}{K_{c}}\right)^{\frac{3}{4}}}
$$

The parameters in the formula are: radius $R$ of grinding wheel, angular velocity_ $\omega$ of grinding wheel, cutting depth $a_{p}$, linear velocity $v_{s}$, feed speed $v_{w}$, grinding width $\mathrm{b}$, grinding particle radius $r$, hardness $\mathrm{H}$ of workpiece material, fracture plasticity $K_{o}$ number of grinding particles $n$, ratio coefficient $\delta_{1}, \delta_{2}$, contact force $P_{m}$ of single grit, ultrasonic vibration frequency $\mathrm{f}$, transverse crack width $C_{1}$, grinding particle fraction Cloth density $N_{d s}$ ultrasonic amplitude A.

According to the above formulas, if the processing parameters of ordinary grinding are known, the critical frequency of ultrasonic grinding can be deduced according to the formulas. After obtaining the critical frequency, the corresponding frequency width can be taken as the working frequency of ultrasonic assisted grinding, and the better effect of ultrasonic assisted grinding can be obtained. On the contrary, if the parameters of the ultrasonic system are known, the grind- 
ing parameters can also be obtained by inverse equation.

\subsection{Critical Amplitude of Ultrasound System}

The critical amplitude of the ultrasonic system is mainly determined by the surface abrasive particle distribution density $N_{d s}$ of the grinding wheel. As shown in Figure 4, the trajectory of the cross-row abrasives on the grinding wheel does not interfere when the spacing of the cross-row Abrasives equals the width of the transverse crack plus the length of the amplitude by two times. When the amplitude is greater than $1 / 2$ of the abrasive spacing, the trajectories of the crossrow abrasives are superimposed on each other. Therefore, once the size of grinding wheel is selected, the critical amplitude can be determined. The critical ultrasonic amplitude can be obtained by the following formula:

$$
A=\frac{h-n h_{1}}{2 n}-C_{1}
$$

In the formula, $A$ is the critical amplitude, $h$ is the width of grinding wheel, hlis the width of abrasive indentation, $n$ is the number of longitudinal abrasive particles, $C_{1}$ is the length of transverse crack. When the ultrasonic amplitude, grinding depth and transverse crack length are known, if there are only two rows of abrasive particles on the surface arc of the grinding wheel contacting the workpiece, the trajectory (crack) of the longitudinal abrasive particles will not interfere. Therefore, the spacing of longitudinal abrasives is determined by the radius of grinding wheel and the grinding depth, and the spacing of transverse Abrasives can be determined by Equation (22). When the number of abrasive particles is known, the critical distribution density of abrasive particles can be obtained by calculation. This method can be used to design the special grinding wheel for ultrasound.

\subsection{Grinding Force Modeling}

Assuming that $\xi_{1} \xi_{2}=\xi$, the substitution formula (11)-(13) can be obtained:

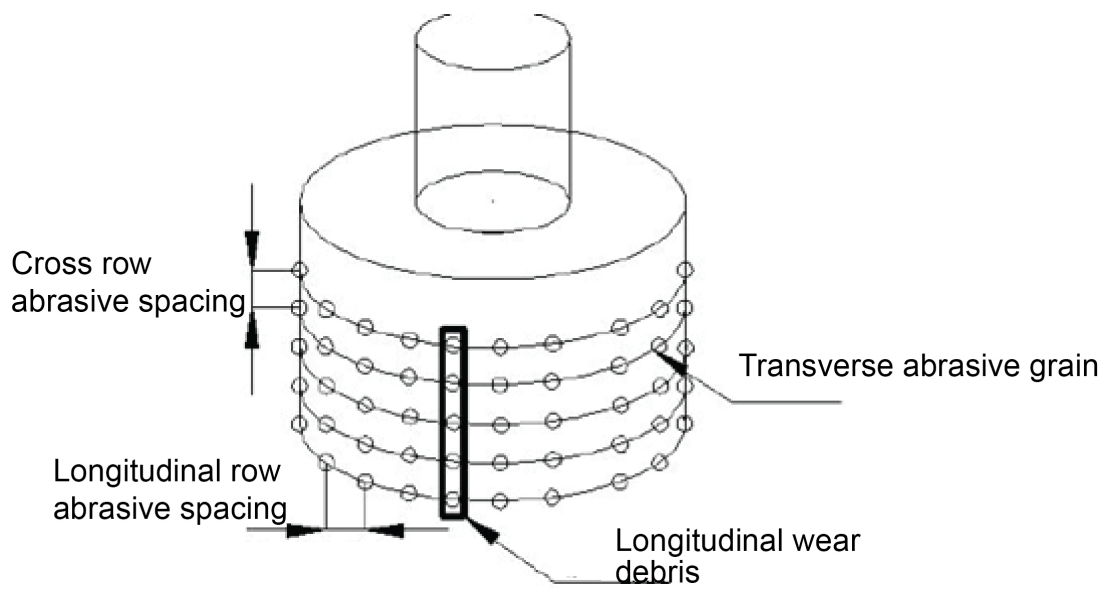

Figure 4. The ideal grinding wheel surface grain distribution. 


$$
\begin{aligned}
& 2 \xi N_{d s} v_{s}\left(\frac{P_{m}}{K_{c}}\right)^{\frac{3}{4}}\left(\frac{P_{m}}{H}\right)^{\frac{1}{2}} \int_{0}^{t_{1}} \sqrt{\left(v_{w}+v_{s}\right)^{2}+\left(2 \pi f A \cos \left(2 \pi f t_{1}\right)\right)^{2}+\left(v_{s} \sin w t_{1}\right)^{2}} \mathrm{~d} t_{1}(10) \\
& =v_{w} a_{p}
\end{aligned}
$$

By calculating $\zeta$ through indentation test, the grinding force $p_{m}$ of a single abrasive particle can be calculated, and then the total grinding force can be obtained [1]-[6].

Grinding force of a single abrasive particle:

$$
P_{m}=\sqrt[5]{K_{c}^{3} H^{2}\left(\frac{v_{w} a_{p}}{2 \xi N_{d s} v_{s} \int_{0}^{t_{1}} \sqrt{\left(v_{w}+v_{s}\right)^{2}+\left(2 \pi f A \cos \left(2 \pi f t_{1}\right)\right)^{2}+\left(v_{s} \sin w t_{1}\right)^{2} \mathrm{~d} t_{1}}}\right)^{4}}
$$

Overall grinding force:

$$
F=N_{d s} b v_{s} \sqrt{K_{c}^{3} H^{2}\left(\frac{v_{w} a_{p}}{2 \xi N_{d s} v_{s} \int_{0}^{t_{1}} \sqrt{\left(v_{w}+v_{s}\right)^{2}+\left(2 \pi f A \cos \left(2 \pi f t_{1}\right)\right)^{2}+\left(v_{s} \sin w t_{1}\right)^{2} \mathrm{~d} t_{1}}}\right)^{4}}
$$

From the mathematical model of grinding force, it can be seen that grinding force decreases with the increase of frequency, amplitude, cutting depth and grinding width, and feed speed. According to formula (25), the numerical simulation of grinding force $\mathrm{F}$ is as follows:

The calculated grinding force shown in Table 1 is an average value which can reflect the average grinding force per unit removal volume. In fact, the removal

\begin{tabular}{|c|c|c|c|c|c|c|c|}
\hline $\begin{array}{c}\text { Grinding wheel } \\
\text { speed }\end{array}$ & Feed rate & $\begin{array}{c}\text { Radius of } \\
\text { abrasive grains }\end{array}$ & $\begin{array}{c}\text { Grinding } \\
\text { wheel radius }\end{array}$ & $\begin{array}{l}\text { Grinding } \\
\text { depth }\end{array}$ & frequency & amplitude & Grinding force \\
\hline $\mathrm{v}_{\mathrm{s}}(\mathrm{r} / \mathrm{min})$ & $\mathrm{v}_{\mathrm{w}}(\mathrm{mm} / \mathrm{min})$ & $\mathrm{r}(\mu \mathrm{m})$ & $\mathrm{R}(\mathrm{mm})$ & $\mathrm{a}_{\mathrm{p}}(\mathrm{mm})$ & $\mathrm{f}(\mathrm{Hz})$ & $\mathrm{A}(\mu \mathrm{m})$ & $\mathrm{F}(\mathrm{N})$ \\
\hline 2200 & 420 & 108 & 11 & 0.04 & 16000 & 7 & 25.16 \\
\hline 2200 & 420 & 108 & 11 & 0.04 & 20000 & 7 & 25.00 \\
\hline 2200 & 420 & 108 & 11 & 0.04 & 24000 & 7 & 24.85 \\
\hline 2200 & 420 & 108 & 11 & 0.04 & 28000 & 7 & 23.70 \\
\hline 2200 & 420 & 108 & 11 & 0.04 & 30000 & 7 & 24.55 \\
\hline 2200 & 420 & 108 & 11 & 0.04 & 16000 & 13 & 24.55 \\
\hline 2200 & 420 & 108 & 11 & 0.04 & 20000 & 13 & 24.09 \\
\hline 2200 & 420 & 108 & 11 & 0.04 & 24000 & 13 & 23.48 \\
\hline 2200 & 420 & 108 & 11 & 0.04 & 28000 & 13 & 22.87 \\
\hline 2200 & 420 & 108 & 11 & 0.04 & 30000 & 13 & 22.49 \\
\hline
\end{tabular}
rate of AUAG varies with the change of ultrasonic amplitude and frequency. As shown in Figure 5 the grinding force decreases with the increase of ultrasonic

Table 1. Grinding force calculation sheet. 


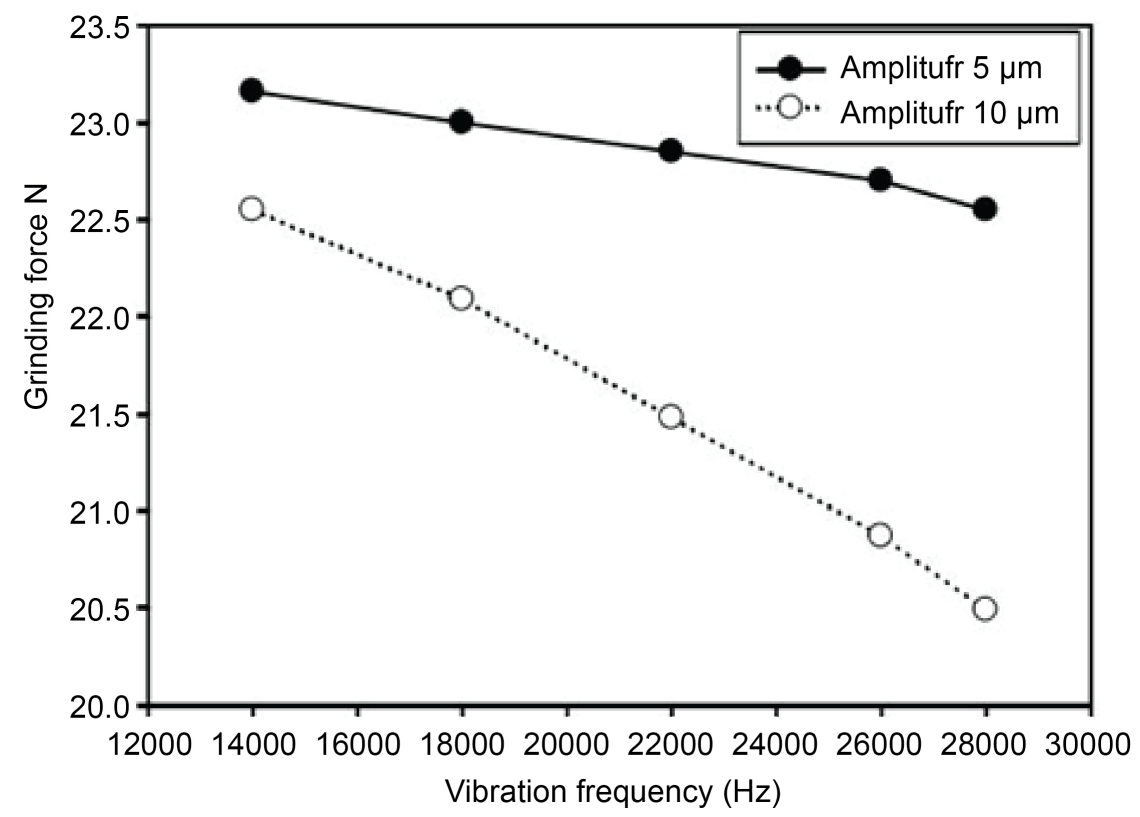

Figure 5. Predicted relation between grinding force and frequency.

frequency and further decreases with the increase of ultrasonic amplitude. In addition, the prediction model shows that the grinding force increases with the increase of grinding depth, feed speed and grinding width. The above formulas show that the ultrasonic parameters have a great influence on the grinding force and surface quality. The ultrasonic frequency and amplitude can change the performance of ultrasonic vibration assisted grinding. The matching of ultrasonic system is necessary for ultrasonic grinding.

\section{Experiment Setup}

In order to verify the accuracy of the mathematical model, specific experimental studies, experimental equipment and testing methods are carried out. The specific experimental settings are as follows. SiN, relative density $3.18\left(\mathrm{~g} / \mathrm{mL}, 25^{\circ} \mathrm{C}\right)$, Mohr hardness 9, small coefficient of thermal expansion, good chemical stability and excellent oxidation resistance were selected as experimental materials. The size is $40 \mathrm{~mm} \times 25 \mathrm{~mm} \times 7 \mathrm{~mm}$, as shown in Figure 6 .

Table 2 is the experimental parameter matrix, which characterizes the parameter settings in the experiment. Four output variables, material removal rate, grinding force, surface roughness and surface micro-morphology, can be obtained through experiments. Through the matching equation of the ultrasonic system, the critical frequency of the ultrasonic vibration is $13,000 \mathrm{~Hz}$.

\section{Results and Discussion}

By comparing the experimental results of conventional grinding and ultrasonic vibration assisted grinding, the effects of ultrasonic vibration frequency and amplitude on the processing quality were studied. All the experiments were divided 
Table 2. Matrix for the parametric experiments.

\begin{tabular}{|c|c|c|c|c|c|c|c|}
\hline Grouping & $\begin{array}{c}\text { Grinding } \\
\text { wheel speed }\end{array}$ & $\begin{array}{c}\text { Radius of } \\
\text { abrasive grains }\end{array}$ & Feed rate & frequency & amplitude & $\begin{array}{c}\text { Grinding } \\
\text { wheel radius }\end{array}$ & $\begin{array}{l}\text { Grinding } \\
\text { depth }\end{array}$ \\
\hline & $\mathrm{v}_{\mathrm{s}}(\mathrm{r} / \mathrm{min})$ & $\mathrm{r}(\mu \mathrm{m})$ & $\mathrm{v}_{\mathrm{w}}(\mathrm{mm} / \mathrm{min})$ & $\mathrm{f}(\mathrm{k} \mathrm{Hz})$ & $\mathrm{A}(\mu \mathrm{m})$ & $\mathrm{R}(\mathrm{mm})$ & $a_{p}(m m)$ \\
\hline 1 & $800-2200$ & 108 & 420 & 16 & 7 & 11 & 0.04 \\
\hline 2 & $800-2100$ & 108 & 420 & 31 & 13 & 11 & 0.04 \\
\hline 3 & $800-2100$ & 108 & 420 & 0 & 0 & 11 & 0.04 \\
\hline 4 & 800 & 108 & $108-420$ & 16 & 7 & 11 & 0.04 \\
\hline 5 & 800 & 108 & 420 & 16 & 7 & 11 & $0.007-0.04$ \\
\hline 6 & 800 & 108 & $108-420$ & 31 & 13 & 11 & 0.04 \\
\hline 7 & 800 & 108 & 420 & 31 & 13 & 11 & $0.007-0.04$ \\
\hline
\end{tabular}

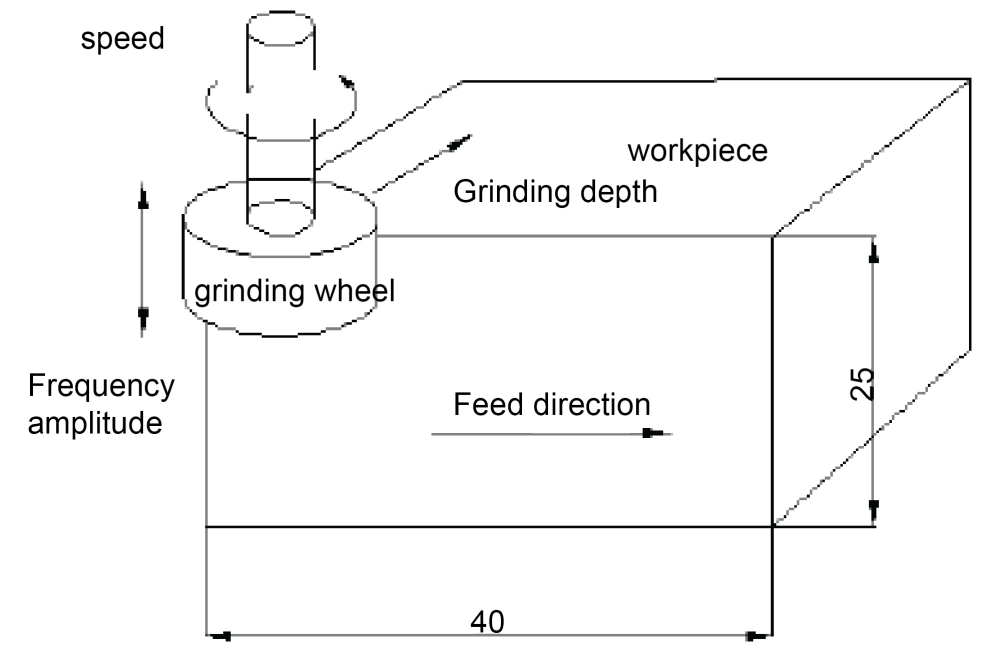

Figure 6. Relative position between workpiece and tool.

into seven groups for 28 times, with different ultrasonic amplitudes and frequencies. After each group of experiments, the grinding wheel is sharpened to prevent the influence of wheel wear on the experimental results. LY-WN-YH Ultra-depth-of-field microscopy is used to collect three-dimensional micro-topography of grinding surface. NANOVEA ST400 Surface profilometer is used to measure the roughness of grinding surface. In order to obtain effective data, the experiment was repeated three times, and the final average value was obtained as the experimental result. The surface morphology and grinding force analysis obtained by grinding are shown in the following figure.

The workpiece surface debris produced by ultrasonic vibration assisted grinding is much less than that produced by conventional grinding. This shows that ultrasonic vibration can effectively clean grinding debris and prolong the service life of grinding wheel. Compares the grinding surface obtained by different ultrasonic parameters. It can be seen that the surface roughness of ultrasonic grinding is lower than that of ordinary grinding, but the surface morphology of high 
frequency is worse than that of low frequency. NANOVEA ST400 three-dimensional profilometer is used to measure different surface topography.

The machined surface obtained by low frequency ultrasonic vibration assisted grinding is the best, with low surface ripple and surface roughness. The surface obtained by high frequency ultrasonic machining is relatively worse than that by low frequency machining, but still better than that by ordinary grinding. This shows that the roughness of machined surface increases with the increase of frequency when ultrasonic grinding is used on critical frequencies. The matching of ultrasonic system plays a macro-control role on the quality of surface processing. It is very important to optimize the parameters of ultrasonic grinding. The influence of ultrasonic parameters on grinding force is shown in the following figure.

The grinding force of ultrasonic vibration assisted grinding is less than that of ordinary grinding, and is affected by the ultrasonic amplitude and frequency. The grinding force decreases with the increase of ultrasonic frequency, amplitude and spindle speed, and with the decrease of grinding depth and feed speed. It shows the comparison between the grinding force measured by the experiment and the simulation value. It can be seen that the change trend of the grinding force under the influence of the ultrasonic parameters (frequency, amplitude) can be consistent with the change trend of the grinding force measured by the experiment. The experimental results can validate the correctness of the mathematical model effectively, and better ultrasonic grinding parameters can be obtained through the system matching model of brittle materials.

\section{Conclusion}

Through a comprehensive study of the processing mechanism of hard and brittle materials, a system matching model of ultrasonic vibration assisted grinding of brittle materials is established. The model is used to reveal the grinding principle of ultrasonic vibration assisted grinding and optimize the processing parameters of ultrasonic grinding, so as to improve the processing quality. Based on the mathematical model, the critical frequency of the ultrasonic system increases with the increase of wheel speed, feed speed and abrasive particle distribution density, and decreases with the decrease of grinding depth and feed speed. The frequency and amplitude of ultrasonic vibration have great influence on material removal rate, grinding force, surface morphology and surface roughness. Ultrasound grinding of brittle materials needs to select the best ultrasonic parameters to obtain the best surface quality. The grinding force increases with the increase of the number of abrasive particles, grinding depth, grinding width and feed speed, and decreases with the increase of ultrasonic vibration frequency, ultrasonic amplitude and spindle speed. The matching model of ultrasonic system can be used to optimize the ultrasonic processing parameters of hard and brittle materials, predict the grinding surface morphology, grinding force and surface roughness. 


\section{Fund Support}

Supported by Natural Science Foundation of Hunan Province. Item number: $2017 J J 5056$.

Entry name: Study on the mechanism of ultrasonic precision grinding of carbon fiber composites.

\section{Conflicts of Interest}

The author declares no conflicts of interest.

\section{References}

[1] Wu, Y., Sun, A.G., Zhao, B. and Zhu, X.S. (2016) Study on High Efficiency Removal Mechanism of Ceramic Material by Ultrasound Vibration Grinding. Manufacturing Technology and Machine Tools, 4, 59-62.

[2] Gong, Y.B., Liu, J., Shen, J.Y. and Xu X.P. (2015) Contrastive Experimental Study on Grinding and Polishing of Si C Ceramics by Two Processing Methods. Superhard Material Engineering, 6, 7-10.

[3] Xiang, D.H., Liu, J.H., Zhi, X.T. and Zhao, B. (2018) Study on Ultrasound Vibration Ductility Domain Grinding Characteristics of Nano- $\mathrm{ZrO}_{2}$ Ceramics. Indian Journal of Engineering and Materials Sciences, 43, 30-34.

[4] Zhao, B., Wu, Y., Liu, C.S., Gao A.H. and Zhu, X.S. (2016) The Study on Ductile Removal Mechanisms of Ultrasonic Vibration Grinding Nano- $\mathrm{ZrO}_{2}$ Ceramics. Key Engineering, 304-305, 171-175. https://doi.org/10.4028/www.scientific.net/KEM.304-305.171

[5] Kremer, D. (2016) New Developments on Ultrasonic Machining, Society of Manufacturing Engineers, 2016. SME Technical Paper, MR91-522, p. 13.

[6] Wang, X., Zhou, M., Gan, J.G.K. and Ngoi, B. (2016) Theoretical and Experimental Studies of Ultraprecision Machining of Brittle Materials with Ultrasonic Vibration. The International Journal of Advanced Manufacturing Technology, 20, 99-102. https://doi.org/10.1007/s001700200130 